\title{
Initializing multi-stakeholder engagement in the context of Marine Protected Area management and capacity-building programmes: A Tun Mustapha Park case study
}

Sharlene S. Boey ${ }^{1,2}$, Wan Nur Syazana Wan Mohamad Ariffin ${ }^{1,2}$, Affendi Yang Amri ${ }^{2,4}$, Sandra Liew $^{1,2}$, Voon-Ching Lim ${ }^{1,2}$, Kamal Solhaimi Fadzil ${ }^{2,5}$, Julia Suhaimi ${ }^{2,6}$, Muhammad Ali Syed Hussein ${ }^{1,7}$, Amy Yee Hui Then ${ }^{2,3,4}$, Hong Ching Goh ${ }^{1,2, *}$

\author{
${ }^{1}$ GCRF Blue Communities, University Malaya, 50603 Kuala Lumpur, Malaysia \\ ${ }^{2}$ Department of Urban and Regional Planning, Faculty of Built Environment, University of \\ Malaya, 50603 Kuala Lumpur, Malaysia \\ ${ }^{3}$ Institute of Biological Sciences, Faculty of Science, University of Malaya, 50603 Kuala Lumpur, \\ Malaysia \\ ${ }^{4}$ Institute of Ocean and Earth Sciences, University of Malaya, 50603 Kuala Lumpur, Malaysia \\ ${ }^{5}$ Department of Anthropology and Sociology, Faculty of Arts and Social Sciences, University of \\ Malaya, 50603 Kuala Lumpur, Malaysia \\ ${ }^{6}$ Department of Primary Care Medicine, Faculty of Medicine, University of Malaya, 50603 Kuala \\ Lumpur, Malaysia \\ ${ }^{7}$ Endangered Marine Species Research Unit, Borneo Marine Research Institute, Universiti \\ Malaysia Sabah, Jalan UMS, 88400 Kota Kinabalu, Sabah
}

\section{"Corresponding author email:} gohhc@um.edu.my

Received date: 2 Nov 2018 Published date: 31 Dec 2018

\section{How to cite:}

Boey, S., Wan Mohamad Ariffin, W., Yang Amri, A., Liew, S., Lim, V., Fadzil, K., Suhaimi, J., Syed Hussein, M., Then, A., \& Goh, $H$. (2018). Initializing multistakeholder engagement in the context of Marine Protected Area management and capacitybuilding programmes: A Tun Mustapha Park case study. Journal of Research Management \& Governance, 1(1), 31-37. Retrieved from https:// ejournal.um.edu.my/index.php/ JRMG/article/view/14490

DOI:

https://doi.org/10.22452/

jrmg.vol1no1.2

\begin{abstract}
As global trends in Marine Protected Area (MPA) management shift towards participatory co-governance, the importance of effective stakeholder engagement in its implementation stages warrant greater emphasis. This case study highlights key lessons learned from the employment of a mixture of focus group discussions (FGDs), interviews and reconnaissance surveys in a preliminary study-site visit to Tun Mustapha Park (TMP), Sabah, Malaysia, where our research team is undertaking a 4-year research and capacity-building project. We found that trust building, understanding the local culture and politics, and recognition of complex stakeholder dynamics were key elements to successful engagement, while identifying key decision-makers for followups were crucial for on-going engagement. This paper presents insights into the types of information collected by our team, which would be useful among conservation practitioners who will be conducting similar engagement work in the future.
\end{abstract}

Keywords: multi-stakeholder engagement; marine protected areas; capacity-building; marine management; co-governance 


\section{INTRODUCTION}

As coastal populations grow exponentially, there is a burgeoning need to reconcile socio-economic demands and biodiversity protection goals (Klein et al., 2008; Mills et al., 2016). Marine Protected Areas (MPAs) have been used globally as a management tool for conservation of marine ecosystems and biodiversity; yet neglecting certain interests within its social landscape can lead to stakeholder conflicts and non-compliance (Fernandez, 2007). In response, governments and marine park managers are increasingly adopting more socially inclusive forms of governance as opposed to highly institutional ones as a hopeful solution. The recent shift to a more inclusive governance approach, known as 'cogovernance', is also a result of its positive track record in fostering cooperation between local communities and MPA planners - a much desired social situation for effective MPA management where human and financial resources for enforcement are typically scarce (Evans, Cherett, \& Pemsl, 2011).

In Malaysia, the governance of MPAs have historically been top-down and is often compounded by management complexities and power overlaps (Islam et al., 2017). For instance, the establishment of marine parks fall under both the jurisdictions of the Sabah Wildlife Department and the Department of Marine Park Malaysia; yet the former reports to the State government and the latter works under the Federal government. Malaysian MPAs have also traditionally been designated as 'no-take', namely all forms of resource extractions are strictly prohibited, consequently changing the economic landscape for local communities who depend directly on its marine resources for food and a primary source of income (Islam et al., 2017). In recent years, however, the global recognition of artisanal communities' rights, coupled with advancements in spatial planning technology have promoted more inclusive forms of governance (Cinner \& Aswani 2007; Klein, Steinback, Watts, Scholz, \& Possingham, 2010). In Sabah, government agencies and non-governmental organizations (NGOs) have also sought to develop MPA frameworks which incorporate community consultations to ensure locations for biodiversity preservation are unanimously agreed upon while the freedom to fish in other locations are prescribed to varying degrees (Jumin et al., 2017; Sabah Parks, 2017).

The Tun Mustapha Park (TMP), off the north coast of the state of Sabah, covers an area of $8988 \mathrm{~km}^{2}$ and was established in May 2016 as the first multiple-use marine park in Malaysia following a 13-year participatory and consultative process facilitated by WWF-Malaysia and Sabah Parks (Langenheim, 2016; WWF-Malaysia, 2017). As the largest MPA in Malaysia which supports an abundance of marine life and ethnically diverse communities, TMP is collaboratively managed by multiple stakeholders based on the concept of co-governance involving community participation at all stages of implementation (Sabah Parks, 2017; WWF-Malaysia, 2017). While a multitude of past case-studies have discussed methods to stakeholder engagement in MPA spatial planning processes (Pomeroy \& Douvere, 2008; Ritchie \& Ellis, 2010; Gopnik et al., 2012), few have assessed stakeholder engagement during implementation stages where capacity-building, recognised as a cornerstone for active participation of stakeholders and knowledge-sharing (Cuthill \& Fien, 2005), is a central focus.

Blue Communities is a 4-year programme funded by the UK Government's Global Challenges Research Fund (GCRF) to support the ongoing implementation and management of marine ecosystems across four case-study sites in Southeast Asia: Malaysia, Indonesia, Philippines and Vietnam. The core objective of the programme is to develop interdisciplinary research capabilities, which in turn would encourage knowledge exchange and collaboration with local stakeholders to enhance the existing management plans for MPA. As a country partner to Blue Communities, the University of Malaya have sought to work with stakeholders in TMP to provide support in achieving the management's mission for biodiversity protection, sustainable development, and poverty alleviation (Sabah Parks, 2017). 
Here we discuss our techniques used to initiate engagement with stakeholders during our first site visit to TMP in March 2018. The objectives of this paper are to provide insights into the types of information gathered through engagement methods, discuss associated challenges, and present lessons learned.

\section{STAKEHOLDER ENGAGEMENT METHODS}

\subsection{Objective Setting}

To initiate engagement with stakeholders, we designed a site visit to TMP which aimed to (i) introduce the project to TMP stakeholders, (ii) identify knowledge gaps and issues related to marine spatial planning in the marine park, (iii) set key progress milestones for monitoring and evaluation among team members, and (iv) conduct reconnaissance surveys at various islands located within the TMP boundary. Engagement approaches included a stakeholder meeting with focus group discussions, open-ended interviews and reconnaissance surveys.

\subsection{Focus Group Discussions (FGDs)}

We invited a range of representatives from government, NGOs, the local community and private sector to a stakeholder meeting in the state capital of Sabah, Kota Kinabalu. The invitation list included all key decision-makers, influential societies and known community groups. Consequently, 27 stakeholder groups attended the 1-day meeting hosted by the University of Malaya.

The meeting was divided into four sessions: (1) What is the current state of TMP and the major ecosystem services provided? (2) Future aspirations for a sustainable TMP and how do we get there? (3) Challenges and issues to reach aspirations, and (4) Stakeholder analysis. To stimulate discussions with varied opinions and perspectives, participants were divided into four groups, each of which consisted of representatives from each sector - government, NGO, tour operators and local community, facilitated by one of our team members. Participants were briefed on the objectives of the meeting, the voluntary nature of their participation and their right to leave at any time without reason. Written informed consent was obtained from each participant.

The topic for each session was introduced to the participants and they were free to discuss the topics within the assigned groups based on their experiences and knowledge. Tools such as sticky notes and maps were used to encourage discussion within the groups. In Session 1, participants at each table drew a mind map on flipchart paper and used sticky notes to link the ecosystem services and associated threats. In session 2, the participants wrote statements on their future aspirations for TMP on flipchart paper. In session 3, the participants discussed challenges and potential solutions related to society, economy, environment, health, governance and technology in TMP; the resulting points of discussion were written on sticky notes and placed on a map of TMP. Finally, in session 4, participants collectively drew influence-importance matrices on flipchart paper. After each session, a plenary session was held where the results of the discussion were presented by representative of each group. When the stakeholder meeting was over, participants were handed feedback and evaluation forms, and team members ran a post-mortem analysis to collate the information resulted from the meeting.

\subsection{Interviews}

Following the stakeholder meeting, team members travelled to the largest and most populated island in TMP, Banggi Island, to conduct informal interviews with local groups (i.e. youth club, fisher association, health group, and a privately-run homestay) to understand the socio-economic situation in the island. 
Interviews were carried in an informal fashion with open-ended questions, where interviewees took the lead in the conversation allowing team members to note their interests and sentiments without interruption. Questions were framed to gain insights into an organisation's activities, which stakeholders they worked closely with, trends they observed, and personal aspirations for the marine park.

\subsection{Reconnaissance Surveys}

The team also conducted reconnaissance surveys at several locations including beaches, villages, a copra processing farm, mangrove forest, and bagang (a traditional wooden structure with a large net used to catch anchovies at the seaside) (Mohd Ariff \& Mohammad Raduan, 2008). Observations were made on infrastructure conditions, lifestyle (i.e. nomadic, types of fisheries they involved in), general health of ecosystems, cleanliness, water supply, and demographic factors (i.e. religion, ethnicity).

\section{LESSONS LEARNED AND RECOMMENDATIONS}

\subsection{Mutual Trust among Stakeholders}

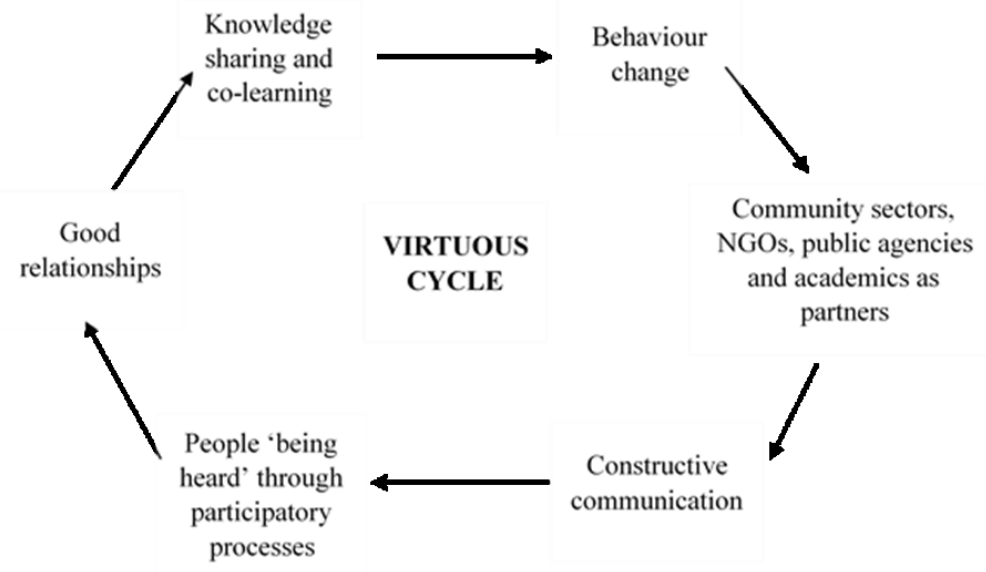

Figure 1: Virtuous cycle of contact brought about by capacity-building and collaborative partnerships amongst stakeholders as adapted from Cuthill \& Fien (2005)

Results of the engagement methods employed over the course of the site visit provided a range of lessons for our team. Firstly, our team learned that utilising the right tools to encourage equal participation was key to creating a neutral environment for open sharing among stakeholders. For example, at FGD groups where more prominent or dominant personalities were present, the wealth of information recorded tended to be from a single person's point of view, whereas other present participants were observed to be relatively passive or quiet. Dominance can also cause a diversion from intended topics of discussion (Wong, 2008) and our team found the use of tools such as sticky notes helpful in steering the direction of conversation, minimising dominance, and encouraging participation from less vocal participants. Such constructive communication is an important step in having all voices heard and to reinforce the 'virtuous cycle of contact' which further promotes cooperation (Figure 1) (Cuthill \& Fien, 2005).

Our team also learned that a prerequisite for effective ongoing engagement was mutual trust among stakeholders. In complex socio-ecological systems such as MPAs, understanding the local communities' concerns, priorities and needs are a pivotal step to building this trust (Jones \& Wells, 2007). We found that carrying out informal, open-ended interviews at their homes or work spaces 
provided a safe-space for open sharing sessions which helped the team understand specific community resource needs while fostering a mutual sense of trust and respect. For example, one respondent described the challenges in meeting the steep reporting requirements of funding bodies when seeking support for alternative livelihoods projects such as woven handicrafts.

\subsection{Understanding Stakeholder Dynamics}

The FGDs helped us understand stakeholder dynamics and perspectives on conservation and management of TMP to further inform engagement strategies. This understanding of complex stakeholder dynamics, often captured through either consensus or disagreement in opinions, is also consistently a key finding from FGDs across a wealth of global conservation literature (Ochieng et al. 2017). For example, we interpreted the management to strongly prioritise community interests in their work through their expression of understanding towards the inequitable effects of weak enforcement of zoning plans on artisanal fishers' access to fishing grounds. We also noted conflicting opinions on the level of inclusivity in zoning plans reflecting the ongoing bargain between stakeholder groups. Such divergences in opinions have also proved characteristic of communities with varying levels of administrative diversity and development as shown in a study on a small-scale marine reserve in Indonesia (Crawford, Kasmidi, Korompis, \& Pollnac, 2006).

\subsection{Type of Information Gathered}

The various engagement methods employed returned various types of information. The FGDs provided a snapshot of concerns and priorities of TMP stakeholders including the need for family planning, the frequency of illegal fish bombing, the marginalization of minority groups, need for proper waste management, land development plans, and access to healthcare and clean water. Through interviews, we were able to capture the finer details of livelihoods of the community including fishermen income, the distance travelled to closest markets, the level of competition between and among commercial and artisanal fishers, other forms of side income, and perceived threats to their welfare. Finally, the reconnaissance surveys resulted in many important observations including set-ups of rainwater harvesting set-up, water wells located near burial sites, shortage in power and water supply, unmanaged garbage along village proximate beaches, and lack in basic infrastructure. While reconnaissance surveys often produce biased results as they are usually conducted along accessible routes as opposed to at random, they are useful in giving a quick general understanding of the area and important background information for future work on-site (Hurst \& Allen, 2007).

\subsection{Failure and Recommendations}

In summary, lessons learned from the TMP site visit include the importance of developing mutual trust among primary stakeholders, understanding of local cultural and political context, and recognising complex stakeholder dynamics - all of which are factors found to contribute significantly to successful MPAs worldwide including in the United States and the Caribbean (Pomeroy \& Douvere 2008; Dalton, Forrester, \& Pollnac, 2010). Our team was unable to meet the third objective of our site-visit to TMP which was to set key progress milestones for monitoring and evaluation. We found that targeted milestones were difficult to determine as feasibility in addressing specific issues such as alternative livelihood development in TMP required further assessments into barriers to implementation, community buy-in, and sustainability of recommended interventions. Therefore, the third objective may have been premature here and hence we suggest that objectives for initial engagement should be 
focused on building trust between researchers and stakeholders, facilitating reflection from stakeholders, and identifying shared goals. Although the engagement techniques used during our team's first engagement with the stakeholders were successful in achieving most of our objectives, there was relatively little face-to-face interaction with individual stakeholder groups. We would recommend that stakeholder meetings and FGDs are strongly complemented with ongoing interaction and courtesy visits to foster trust and maintain positive relationships. In addition to engaging with key influential actors, community engagement should be continuously pursued especially when project goals are communitycentric. Our failure to have a fair representation from the local community at our FGDs is likely due to lack of engagement with them prior to the stakeholder meeting. We recommend future researchers to hold a town hall-esque session with the local community as early into the project as possible to introduce its objectives and contribution to encourage their participation in futures activities (Jones \& Wells, 2007). We also highlight consideration for power homogeneity in FGDs as we found that imbalanced power dynamics (i.e. presence of authority and seniority) may have led to dominance in discussions and biased results (Wong, 2008). This case-study will be relevant to MPA conservation practitioners who are looking to engage in complex governance systems where there are multiple levels of management and numerous stakeholders, particularly where participatory methods and social inclusivity are key considerations in its design.

\section{ACKNOWLEDGEMENTS}

This work has received funding in part from the Global Challenges Research Fund (GCRF) UK via the delivery partner Research and Innovation (UKRI) under grant agreement reference NE/P021107/1 to the Blue Communities project. A special thank you to Sabah Parks and Banggi Coral Conservation Society for their generous logistical support throughout the first stakeholder engagement.

\section{REFERENCES}

Cinner, J. E., \& Aswani, S. (2007). Integrating customary management into marine conservation. Biological Conservation, 140(3), 201-216. https://doi.org/10.1016/j.biocon.2007.08.008

Crawford, B., Kasmidi, M., Korompis, F., \& Pollnac, R. B. (2006). Factors Influencing Progress in Establishing Community-Based Marine Protected Areas in Indonesia. Coastal Management, 34(1), 39-64. https://doi.org/10.1080/08920750500379300

Cuthill, M., \& Fien, J. (2005). Capacity building: Facilitating citizen participation in local governance. Australian Journal of Public Administration, 64(4), 63-80. https://doi.org/10.1111/j.14678500.2005.00465a.x

Dalton, T., Forrester, G., \& Pollnac, R. (2010). Formal co-management arrangements and MPA success in the Wider Caribbean. Proceedings of the 63rd Gulf and Caribbean Fisheries Institute.

Evans, L., Cherrett, N., \& Pemsl, D. (2011). Assessing the impact of fisheries co-management interventions in developing countries: a meta-analysis. Journal of Environmental Management, 92 (8), 1938-1949. https://doi.org/10.1016/j.jenvman.2011.03.010

Fernandez, P. R. (2007). Understanding Relational Politics in MPA Governance in Northeastern Iloilo, Philippines. Journal of Coastal Research, 38-42.

Gopnik, M., Fieseler, C., Cantral, L., McClellan, K., Pendleton, L., \& Crowder, L. (2012). Coming to the table: Early stakeholder engagement in marine spatial planning. Marine Policy, 36(5), 1139-1149. https://doi.org/10.1016/j.marpol.2012.02.012 
Hurst, J., \& Allen, R. (2007). The Recce Method for Describing New Zealand Vegetation - Expanded Manual. Retrieved October 24, 2018, from https://nvs.landcareresearch.co.nz/Content/ Recce_FieldProtocols.pdf

Islam, G. M. N., Tai, S. Y., Kusairi, M. N., Ahmad, S., Aswani, F. M. N., Muhamad Senan, M. K. A., \& Ahmad, A. (2017). Community perspectives of governance for effective management of marine protected areas in Malaysia. Ocean \& Coastal Management, 135, 34-42. https://doi.org/10.1016/ j.ocecoaman.2016.11.001

Jones, L., \& Wells, K. (2007). Strategies for academic and clinician engagement in communityparticipatory partnered research. JAMA, 297(4), 407-410. https:// doi:10.1001/jama.297.4.407

Jumin, R., Binson, A., McGowan, J., Magupin, S., Beger, M., Brown, C. J., ... Klein, C. (2017). From Marxan to management: ocean zoning with stakeholders for Tun Mustapha Park in Sabah, Malaysia. Oryx, 52(4), 775-786. https://doi.org/10.1017/S0030605316001514

Klein, C. J., Chan, A., Kircher, L., Cundiff, A. J., Gardner, N., Hrovat, Y., ... Airamé, S. (2008). Striking a balance between biodiversity conservation and socioeconomic viability in the design of marine protected areas. Conservation Biology: The Journal of the Society for Conservation Biology, 22(3), 691-700. https://doi.org/10.1111/j.1523-1739.2008.00896.x

Klein, C. J., Steinback, C., Watts, M., Scholz, A. J., \& Possingham, H. P. (2010). Spatial marine zoning for fisheries and conservation. Frontiers in Ecology and the Environment, 8(7), 349-353. https:// doi.org/10.1890/090047

Langenheim, J. (2016, May 30). Malaysia establishes a 1-million-hectare marine park. The Guardian. Retrieved from https://www.theguardian.com/world/blog/2016/may/30/malaysia-just-establisheda-one-million-hectare-marine-park

Mills, M., Leon, J. X., Saunders, M. I., Bell, J., Liu, Y., O’Mara, J., ... Hoegh-Guldberg, O. (2016). Reconciling Development and Conservation under Coastal Squeeze from Rising Sea Level. Conservation Letters, 9(5), 361-368. https://doi.org/10.1111/conl.12213

Mohammad Raduan Mohd Ariff \& Mohammad Sharir Mohammad Raduan (2008). The monopoly of Bugis fishermen in bagang industry in the East Coast of Sabah. Borneo Research Journal, 2, 41-57.

Ochieng, N.T., Wilson, K., Derrick, C. J, \& Murkerjee, N. (2017). The use of focus group discussion methodology: Insights from two decades of application in conservation. Methods in Ecology and Evolution, 2018(9), 20-32 https://doi.org/10.1111/2041-210X.12860

Pomeroy, R., \& Douvere, F. (2008). The engagement of stakeholders in the marine spatial planning process. Marine Policy, 32(5), 816-822. https://doi.org/10.1016/j.marpol.2008.03.017

Ritchie, H., \& Ellis, G. (2010). "A system that works for the sea"? Exploring Stakeholder Engagement in Marine Spatial Planning. Journal of Environmental Planning and Management, 53(6), 701-723. https://doi.org/10.1080/09640568.2010.488100

Sabah Parks. (2017). Tun Mustapha Park Integrated Management Plan 2017-2026. Kota Kinabalu: Sabah Parks.

Wong, L. P. (2008). Focus group discussion: A tool for health and medical research. Singapore Medical Journal, 49(3), 256-261.

WWF-Malaysia. (2017). Tun Mustapha Park the Creation of a Marine Protected Area: A Case Study on Malaysia. Petaling Jaya: WWF-Malaysia. 